\title{
Inter-specific Variations in Chiasma Frequencies and Terminalization in Chlorophytum Ker-Gawl.
}

\author{
V.P. Patil and Supriya Gandhi \\ Department of Genetics, M.A.C.S. Research Institute, Pune 411 004, India
}

Accepted August 28, 1987

The genus Chlorophytum Ker-Gawl. belongs to the tribe Anthericinae of the sub-family Asphodeleae of Liliaceae (Engler and Prantl 1930), comprising of about 234 species distributed in tropical and sub-tropical regions. Earlier work on this genus appears to be restricted to chromosome number and morphology (Baldwin and Speese 1951, Boraiah 1966, Datta and Mitra 1968, Sheriff 1967, 1971, Sheriff and Chennaveeraiah 1975, Naik 1976, 1977). Relatively very little information is available on the meiotic chromosome behaviour in the species of this genus. Earlier workers have reported meiosis to be regular with eight bivalents in C. tuberosum and C. laxum (Datta and Mitra 1968, Boraiah 1966, Sheriff and Chennaveeraiah 1975, Naik 1976, 1977). In C. tuberosum Kumar and Rao (1958) have reported chiasma frequency per bivalent, interstitial chiasmata, total chiasmata, and chiasmata per bivalent. Hence, the authors have attempted to study chiasma frequency at late diplotene/dikinesis and metaphase I and coefficient of terminalization in five species of Chlorophytum.

\section{Materials and methods}

Chiasma frequencies in the following Chlorophytum species have been carried out:

$$
\text { Species }
$$

C. laxum $\mathrm{R}$. Br.

C. tuberosum Baker

C. comosum Jacques.

C. glaucum Dalz.

C. orchidastrum Lindl.
Locality

Poona University campus

Poona University campus

Garden plant

Ganapati Pule, Konkan

Purandhar Fort

Anthers at proper stage were squashed in 0.01 acetocarmine; late diplotene/dikinesis and metaphase I plates showing well separated bivalents were sketched at bench level using fluotar oil immersion objective. Data have been recorded from semipermanent preparations.

\section{Results}

Data recorded suggest the number of bivalents to vary in these five species.
Species
C. laxum
No. of bivalents
C. tuberosum
8
C. comosum
8
C. glaucum
14
C. orchidastrum

a) Chiasma frequency at late diplotene/dikinesis

Total number of chiasmata per PMC ranges from 19.4 to 52.2, maximum being in C. glaucum and minimum in C. laxum (Table 1). These variations within the genus might be due to polyploidy present as observed above. However, number of chiasmata per bivalent indicates 

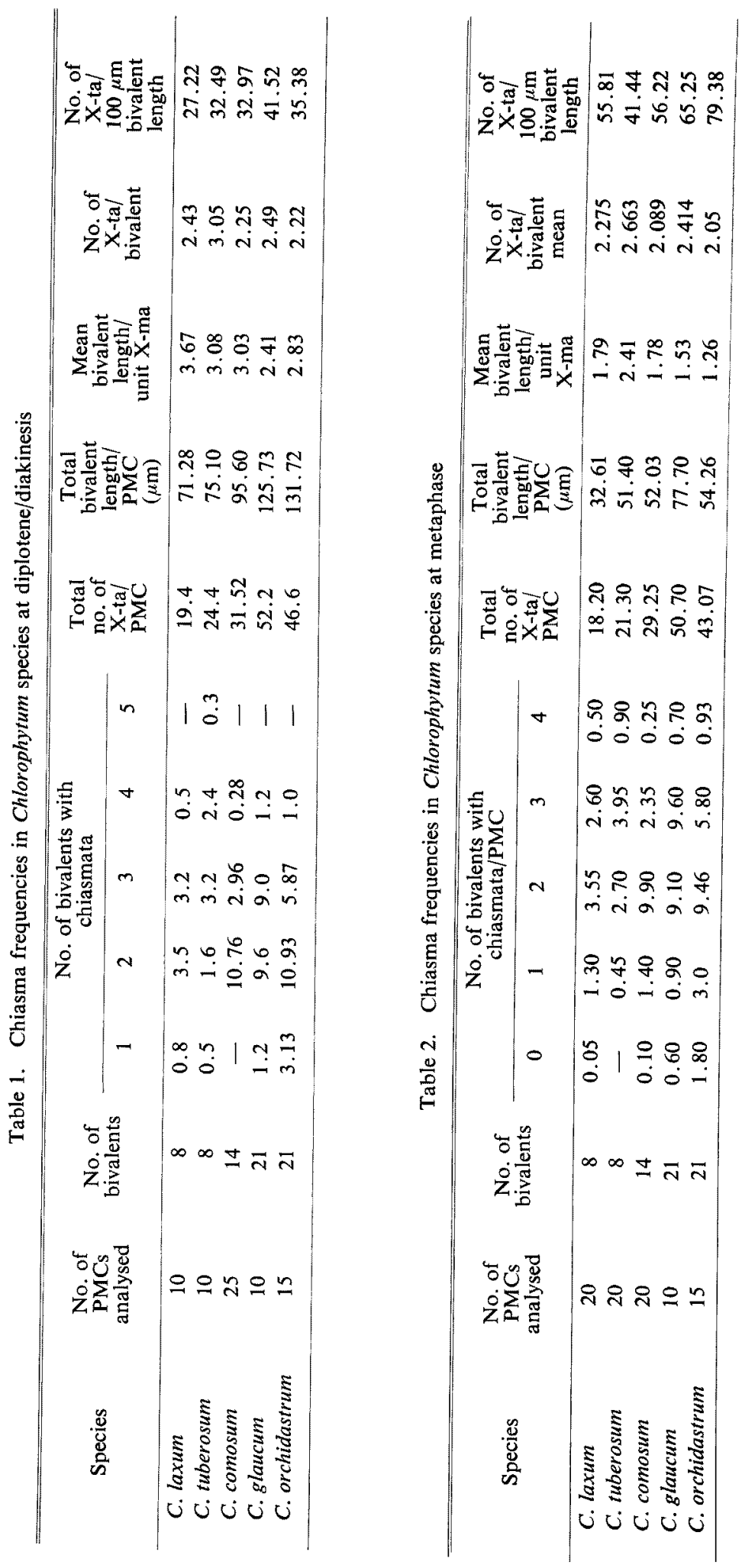
highest values in $C$. tuberosum followed by $C$. glaucum and minimum in $C$. orchidastrum. Number of chiasmata per $100 \mu \mathrm{m}$ of bivalent length is highest in $C$. glaucum and lowest in $C$. laxum. Bivalents with 1 to 5 chiasmata vary in individiual species. It is interesting to note that in $C$. tuberosum bivalents with five chiasmata could be observed. Even the number of bivalents with three chiasmata appears to be more in C. tuberosum.

b) Chiasma frequency at metaphase $I$

Like diplotene, the total number of chiasmata per PMC varies from 18.2 to 50.7 , highest being in C. glaucum and lowest in $C$. laxum. Maximum number of bivalents with zero chiasma is recorded in C. orchidastrum, whereas in C. tuberosum, this category was not represented. Reversely, more number of bivalents with four chiasmata are noted in C. orchidastrum (Table 2).

Number of chiasmata per bivalent and mean bivalent length per unit chiasma appear to follow the same trends like diplotene (highest in C. tuberosum and lowest in C. orchidastrum).

c) Coefficient of terminalization

At diplotene, the number of intersitial chiasmata was more in $C$. glaucum (11.40). In $C$. comosum, these values were the lowest (Table 3). Similar trends have been observed for interstitial chiasmata at metaphase $I$. It is conspicuous to note that the number of interstitial chiasmata at diplotene and metaphase I appears to be more or less same in orchidastrum and glaucum suggesting the possibility of stationary or non-random movement of chiasmata. On the other hand, in remaining species there is decrease in number of interstitial chiasmata at metaphase I.

Table 3. Coefficient of terminalization in Chlorophytum species

\begin{tabular}{|c|c|c|c|c|c|c|c|c|c|}
\hline \multirow[t]{2}{*}{$\begin{array}{c}1 \\
\text { Species }\end{array}$} & \multicolumn{4}{|c|}{$\begin{array}{l}2 \\
\text { Mean chiasma frequency per PMC } \\
\text { at diplotene/diakinesis }\end{array}$} & \multicolumn{4}{|c|}{$\begin{array}{c}3 \\
\text { Mean chiasma frequency per PMC } \\
\text { at metaphase I }\end{array}$} & \multirow{2}{*}{$\begin{array}{c}4 \\
\text { Coefficient } \\
\text { of termina- } \\
\text { lization } \\
3 c / 2 c\end{array}$} \\
\hline & $\begin{array}{l}\text { Inter- } \\
\text { stitial } \\
\quad \text { a }\end{array}$ & $\begin{array}{l}\text { Terminal } \\
\text { b }\end{array}$ & $\begin{array}{l}\text { Total } \\
\mathrm{c}\end{array}$ & $2 \mathrm{~b} / 2 \mathrm{c}$ & $\begin{array}{l}\text { Inter- } \\
\text { stitial } \\
\quad \mathrm{a}\end{array}$ & $\begin{array}{l}\text { Terminal } \\
\mathrm{b}\end{array}$ & $\begin{array}{c}\text { Total } \\
\mathrm{c}\end{array}$ & $3 b / 3 c$ & \\
\hline C. laxum & 4.20 & 15.20 & 19.40 & 0.7835 & 3.60 & 14.60 & 18.20 & 0.8022 & 0.9381 \\
\hline C. tuberosum & 8.90 & 15.50 & 24.40 & 0.6352 & 5.75 & 15.55 & 21.30 & 0.7300 & 0.8730 \\
\hline C. comosum & 3.52 & 28.00 & 31.52 & 0.8883 & 2.85 & 26.40 & 29.25 & 0.9026 & 0.9280 \\
\hline C. glaucum & 11.40 & 40.80 & 52.20 & 0.7816 & 11.00 & 39.70 & 50.70 & 0.7830 & 0.9713 \\
\hline C. orchidastrum & 7.87 & 38.73 & 46.60 & 0.8311 & 7.66 & 35.41 & 43.07 & 0.8221 & 0.9242 \\
\hline
\end{tabular}

\section{Discussion}

Comparative analysis of chiasma frequencies in five species of Chlorophytum suggests the bivalent number in these species to vary from 8 to 14 to 21 due to polyploidy present in the genus, thus confirming the earlier reports for these species (Kumar and Rao 1958, Datta and Mitra 1968, Naik 1976). Presence of univalents in species like orchidastrum and glaucum indicates the differential degree of condensation as also free terminalization ultimately leading to separation as univalents. During diplotene regular bivalents were noted, however, this differentiation takes place from prometaphase onwards. Such differences in univalent frequencies may correspond to parallel differences in random distribution of chiasmata and their free terminalization in undifferentiated homologues.

Close correspondence of mean number of chiasmata per bivalent and mean bivalent length per unit chiasma at both the stages appears to be conspicuous in $C$. tuberosum and C. laxum. This implies random distribution of chiasmata and continuous uninterrupted linear genic homology. Lack of such correspondence possibly due to stationary or nonshifting chiasmata indicates interrupted linear homology. 
Lowest bivalent length per chiasma at metaphase I and high ranking for mean number of chiasmata per bivalent as seen in glaucum suggests (1) frequency being influenced more by bivalent lengths at diplotene rather than metaphase I, and (2) rate of linear condensation from diplotene to metaphase I to be relatively higher.

Interstitial chiasmata at diplotene appear to be more in glaucum, tuberosum and orchidastrum. It is interesting to note that at metaphase I, number of interstitial chiasmata is reduced considerably in tuberosum which implies random distribution, free terminalization and least linear differentiation. On the contrary, in C. glaucum and orchidastrum, though interstitial chiasmata at diplotene are more, there is relatively very little reduction at metaphase I. This clearly indicates the presence of stationary chiasmata with non-random distribution and relatively more linear differentiation.

Comparative account of chiasma frequencies at diplotene and metaphase I and terminalization reveals the possible differentiations among the species under study. In these species the basic chromosome numbers are 8 and 7. Based on the chromosome numbers reported in Chlorophytum, the species with $\mathrm{x}=7$ appear to be more in number as compared to those with $x=8$. This suggests that the species with $x=7$ are relatively more adapted to climatic conditions, or the allotetraploids or polyploids of $x=7$ have developed the fixity and fluidity to withstand the climatic changes, ultimately resulting in the survival of numerous species with $x=7$. The above account on the linear differentiation as observed from the chiasma frequencies and terminalization supports this possibility. On the contrary, laxum and tuberosum with $x=8$ appear to have relatively less linear differentiation possibly due to their restricted occurrence under arid or semiarid conditions. These observations also support the earlier studies on karyotype symmetries (Patil et al.).

\section{Abstract}

Comparative analysis of chiasma frequencies and terminalization in five species of Chlorophytum suggested total number of chiasmata per PMC to be maximum in C. glaucum and minimum in $C$. laxum possibly due to polyploid nature of the species.

Close correspondence of mean number of chiasmata per bivalent and mean bivalent length per unit chiasma suggested least linear differentiation as observed in $C$. laxum and $C$. tuberosum. Reverse situation observed in C. glaucum indicated non-random distribution or stationary chiasmata with relatively more linear differentiation. This has been further confirmed from the stationary interstitial chiasmata at both diplotene/diakinesis and metaphase I stages.

\section{Acknowledgements}

Authors are grateful to Dr. M. S. Kumbhojkar for his help in collection and identification of the species.

\section{References}

Baldwin, J. T. and Speese, B. M. 1951. Cytogeography of Chlorophytum in Liberia. Amer. Jour. Bot. 38: 153-156.

Boraiah, G. 1966. A note on the cytotaxonomy of Chlorophytum laxum R. Br. (Lilliaceae). Curr. Sci. 35: 314-315.

Datta, A. and Mitra, K. 1968. Karyotype analysis in Chlorophytum tuberosum Baker and C. laxum R. Br. Bull, Bot. Surv. India 10: 228.

Engler, A. and Prantl, K. 1930. Die natürlichen Pflanzenfamilien. 2. Auf. Leipzig. 1887-1909.

Kumar, L. S. S. and Shama Rao, H. K. 1958. Chromosome number in Chlorophytum tuberosum Baker. Curr. 
Sci. 27: 406-407.

Naik, V. N. 1976. Chromosomal behaviour and evolutionary trends in Chlorophytum. Bot. J. Linn. Soc. 72: $45-50$.

- 1977. Cytotaxonomic studies of six Indian species of Chlorophytum. Bot. J. Linn. Soc. 74: 297-308. Patil, V.P., Kumbhojkar, M.S. and Gandhi, S.S. 1987. Karyomorphological studies in Chlorophytum Ker-Gawl. Cytologia. 52: 543-550.

Sheriff, A. 1967. Cytological and cytotaxonomic studies in certain members of Liliaceae. Ph. D. Thesis, Bangalore University.

- 1971. Karyomorphological studies in four hexaploid species of Chlorophytum. J. Cytol. and Genet. Congr. Suppl.: 26-32.

- and Chennaveeraiah, M.S. 1975. Cytological studies in Chlorophytum attenuatum complex and cytotaxonomic considerations. Cytologia 40: 401-408. 